\title{
antibodies
}

ISSN 2073-4468

www.mdpi.com/journal/antibodies

Review

\section{Production of Single-Chain Variable-Fragments against Carbohydrate Antigens}

\author{
Yoko Fujita-Yamaguchi ${ }^{1,2}$
}

1 Department of Applied Biochemistry, Tokai University School of Engineering, Hiratsuka, Kanagawa 259-1292, Japan; E-Mail: yokoyamaguchi@tokai-u.jp

2 Department of Molecular and Cellular Biology, Beckman Research Institute of City of Hope, Duarte, CA 91010, USA; E-Mail: yyamaguchi@coh.org; Tel.: +1-626-256-4673; Fax: +1-626-303-8457.

Received: 28 January 2014; in revised form: 18 February 2014 / Accepted: 24 February 2014 /

Published: 12 March 2014

\begin{abstract}
The production of human single-chain variable-fragments (scFvs) against carbohydrate antigens by phage display technology is seemingly a logical strategy towards the development of antibody therapeutics, since carbohydrates are self-antigens. Panning and screening of phages displaying human scFvs using a variety of neoglycolipids presenting structurally-defined carbohydrates resulted in a number of candidate phage clones as judged by cautious evaluation of DNA sequences and specific binding to carbohydrate moieties of interest. $\mathrm{ScFv}$ proteins were expressed in prokaryotic or eukaryotic cells from the respective genes. The characterization of isolated scFvs gene products after establishing expression, production and purification of $\mathrm{scFv}$ protein in different expression systems demonstrated that the production of scFv-human $\operatorname{IgG}_{1} \mathrm{Fc}$ conjugates were originally sufficient in the media of stably-transfected cells, but declined during early passages. Bacterial expression of soluble scFv proteins with binding activity suffered low yields, whereas overexpressed scFv proteins formed inclusion bodies, which required refolding. An insect cell expression system producing soluble and active scFv proteins was found to be cost- and time-effective. The best expression system and fine adjustments for the conditions to prepare active forms had to be determined for each $\mathrm{scFv}$ protein. The successful production of active scFv proteins seems to be dependent on their DNA and/or amino acid sequences.
\end{abstract}

Keywords: anti-carbohydrates; phage display; human antibody; mannotriose; T-antigen; Tn-antigen; $\mathrm{Le}^{\mathrm{x}}$ 


\section{Introduction}

In the current post-genome era, elucidation of carbohydrate modification on the functions of glycoproteins, glycolipids and peptide glycans remains still elusive. We launched a project named "Production of single chain antibodies against a variety of carbohydrate epitopes" in 2003. The aim of the project was to produce a variety of carbohydrate epitope-specific antibodies by phage display technology, so that resulting antibodies could not only provide tools for carbohydrate research, but also be applied to diagnostic and therapeutic uses. This was one of the post-genome glycobiology projects supported by Core Research for Evolutional Science and Technology (CREST) from the Japan Science and Technology Agency.

As is generally known, immunization of animals with carbohydrates often leads to a primary $\operatorname{IgM}$ response. Carbohydrate antigens elicit the T-cell independent response. While rapid and long-lasting, this response does not often generate an $\operatorname{IgM}$ to $\operatorname{IgG}$ switch $[1,2]$. Immunization with peptide mimetics of carbohydrate antigens could thus be one way to overcome the T-cell independent nature of the immune response [3]. Recently acquired knowledge in understanding the T-cell independent immune response and in the key roles that carbohydrates play in cancer growth and metastasis are now being applied to the development of cancer vaccines [2,4]. For our major goal, the in vitro production of anti-carbohydrate antibodies was seemingly a logical and best strategy. Practically speaking, once genes for human single-chain variable-fragments ( $\mathrm{scFvs)}$ ) against carbohydrates are obtained, the production of human IgG can readily be achieved for therapeutic applications. The phage display strategy provides genes encoding recombinant antibodies against the antigens of interest [5]. Phage display technology is also valuable, since it easily allows affinity improvements and other modifications [6,7]. This review summarizes the pros and cons of phage display technology with the major focus on the production of anti-carbohydrate antibodies.

\section{Phage Display Technology in Combination with the Use of Structurally Defined Carbohydrate Probes}

The earlier strategies to produce anti-oncofetal carbohydrate antibodies were achieved by first immunizing animals with cancer-derived materials, such as mucins or cancer cells, as well as cancerous tissues, to produce a whole variety of antibodies, then, afterwards, by determining the specificities of resulting antibodies based on histochemical staining and/or binding affinity for structurally-defined molecules. Histochemical staining of cancer specimens by those antibodies greatly contributed to revealing cancer-specific antigens, including oncofetal T- and Tn-antigens [8].

Later studies utilized glycoproteins, heteroglycans and carbohydrate-bovine serum albumin (BSA) conjugates as antigens to produce anti-carbohydrate single chain antibodies (scFvs) by phage display methods [9-12]. The resulting antibodies included, however, those recognizing not only carbohydrate epitopes, but also carbohydrate and backbone peptide complexes. In contrast, our approach was to use structurally defined neoglycolipids as antigens by adapting phage-display technology to generate human scFvs $[13,14]$. The major reasons we decided on pursuing this strategy were not only to utilize our resources of more than 30 different neoglycolipids readily available at our institute, but also to test whether neoglycolipids can be used as antigens to produce antibodies against desired carbohydrate 
moieties. Carbohydrate antigens, which are soluble by themselves, can be immobilized via lipid anchors on plastic titer-plates for panning and screening to isolate candidate phage antibodies against respective carbohydrate antigens. If successful, the generation of antibodies against structurally defined carbohydrate moieties would become possible, as long as neoglycolipids with the desired carbohydrates could be prepared.

\subsection{Isolation and Characterization of Anti-Trimannose Antibodies by Phage Display Technology} Using Neoglycolipids as Probes

The phage display strategy actually consists of two major components. The panning and screening of phage libraries (Component 1) can result in the isolation of genes encoding recombinant antibodies against any antigens of interest in vitro. The isolated genes then need to be expressed in prokaryotic or eukaryotic cells to produce antibody proteins for further characterization of the respective genes obtained (Component 2). Unless in vitro translation systems are also used in Component 2, anti-carbohydrate antibodies cannot be fully produced in vitro.

These two components are well-presented by our two consecutive papers on producing and characterizing anti-mannotriose (Man3) antibodies [15,16]. The objectives of the first study [15] were to establish a new methodology to obtain scFvs genes encoding anti-carbohydrate moieties and to select candidate $\mathrm{scFv}$ genes for future use. The objective of our second paper [16] was to produce soluble scFv proteins in a quantity, so that purification and characterization of isolated scFvs could be readily accomplished.

To first establish methodologies to build up a set of scFvs directed against various carbohydrate moieties, phage-display libraries representing over $10^{11}$ independent human scFvs were prepared by protocols similar to those in previous reports [17-20]. Mannotriose-dipalmitoylphosphatidylethanolamine (Man3-DPPE) was synthesized from mannotriose (Man3) and dipalmitoylphosphatidylethanolamine (DPPE) by reductive amination as described by $[13,14]$. Detailed procedures for the preparation of the phage library and neoglycolipids have been published [15].

Briefly, 25 sequence-independent clones were isolated using a model neoglycolipid, Man3-DPPE: (Figure 1a). Preliminary analyses of the resulting four phage antibodies and respective scFv protein preparations indicated good affinity and specificity for nonreducing terminal mannose residues [15]. Characterization of positive phage clones by enzyme-linked immunosorbent assay (ELISA), TLC dot-blot assays, as well as TLC overlay assays and surface plasmon resonance (SPR) analyses [15] indicated that the phage antibody clones bound to neoglycolipids bearing mannose residues at nonreducing termini, but did not bind to the lipid by itself. In addition, binding of the phage antibody to RNase B carrying high mannose-type oligosaccharides, but not to fetuin carrying complex-type and $O$-linked oligosaccharides, was observed. Furthermore, first round characterization of scFvs expressed from the respective phages indicated good affinity and specificity for nonreducing terminal mannose residues [15]. This study thus demonstrated the validity of a strategy employing phage display technology in constructing human scFvs against various carbohydrate antigens. 
Figure 1. Carbohydrate probes used for the panning and screening of phages displaying human single-chain variable-fragments ( $\mathrm{scFvs}$ ) proteins by various structurally-defined carbohydrate probes: (a) mannotriose-dipalmitoylphosphatidylethanolamine (Man3-DPPE); (b) Le $^{\mathrm{X}}$ (lacto-N-fucopentaose III (LNFPIII))-DPPE; and (c) T-antigen E6-3,5-bis-8dodecyloxy benzamide (BDB).

a. Man3-DPPE

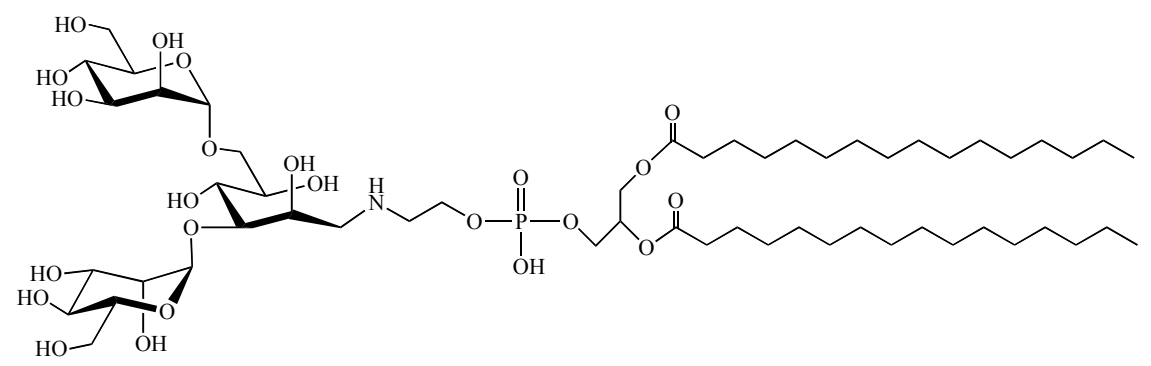

\section{b. Lex(LNFPIII)-DPPE}

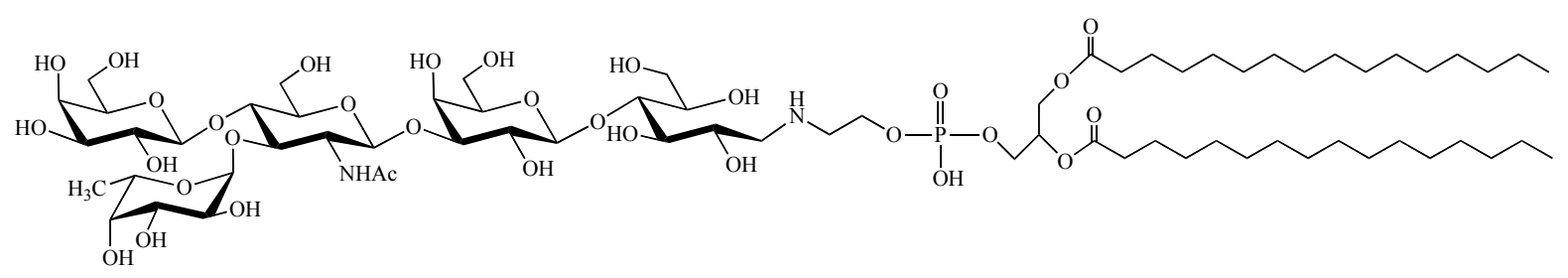

\section{c. T-antigen-E6-BDB}

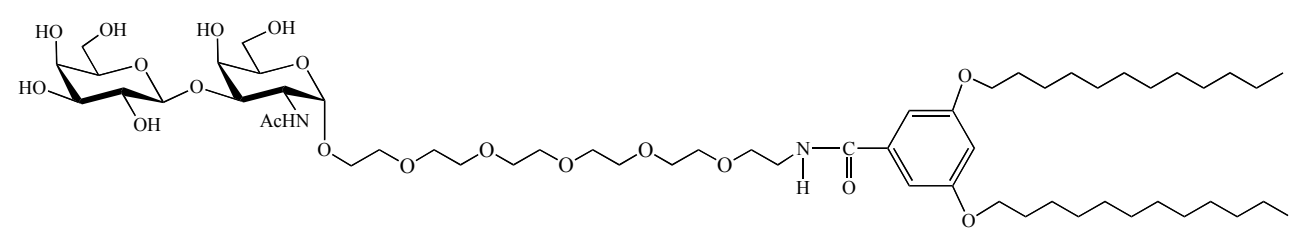

\subsection{Purification and Characterization of Anti-Carbohydrate Antibodies Expressed in Mammalian Cells}

After the preliminary assessments, purified antibody proteins must be prepared from genes retrieved from phages to further characterize the antibodies against the antigen and to develop antibody diagnostics and therapeutics in the future. Our second paper [16] thus described the characterization of the isolated scFvs gene products after establishing the expression, production and purification of $\mathrm{scFv}$ proteins. That study demonstrated that the production of an $\mathrm{scFv}-\mathrm{Fc}$ ( $\mathrm{scFv}$-human $\mathrm{IgG}_{1} \mathrm{Fc}$ conjugates) protein with an affinity constant of $10^{-8} \mathrm{M}$ for Man3-BSA, a rather high binding affinity for an antibody against carbohydrates, is possible [16]. During attempts to establish expression systems for isolated anti-Man3 scFv genes, however, the extreme difficulty of producing anti-Man3 antibodies in mammalian cells became apparent. For example, three independent scFv genes, 1A4, 1G4 and 5A3, were isolated from the human scFv-displaying phage library with Man3-DPPE as an antigen with amino acid sequences and initial characterization as were described previously [15]. Stable 1A4 and 1G4 scFv-Fc clones from these genes were never established in Chinese hamster ovary (CHO) or mouse myeloma (NS0) cells [16]. Stable clones were established from $5 \mathrm{~A} 3 \mathrm{scFv}-\mathrm{Fc}$ gene-transfected NS0 cells, which were subsequently used for purification and characterization of the $\mathrm{scFv}$ gene product as 
the first anti-Man3 antibody [16]. As later became apparent, however, such 5A3 clones stably expressing scFv-Fc no longer had the ability to produce the anti-Man3 antibody during early passages [20].

Similarly, anti-Le ${ }^{\mathrm{x}}$ phages were screened from the same library with lacto-N-fucopentaose III (LNFPIII; Le ${ }^{\mathrm{x}}$ )-DPPE (Figure 1b). Of five phage clones isolated, two scFv genes were constructed to express scFv-Fc proteins in NS0 cells. As was experienced with anti-Man3 scFv-Fc clones, only one anti-LNFPIII clone, 1F12, was successfully produced and purified as an scFv-Fc protein [20]. Although anti-LNFPIII 1F12 and anti-Man3 5A3 scFv-Fc proteins were secreted into media, a decline in scFv-Fc production was observed with both stable clones during early passages. Transient expression of anti-LNFPIII and anti-Man3 scFv-Fc genes in COS-7 cells and subsequent analyses of $\mathrm{scFv}-\mathrm{Fc}$ protein expression revealed the accumulation of translated proteins in the endoplasmic reticulum (ER) for $\mathrm{scFv}$-Fc proteins derived from clones that did not survive as stable clones [20]. That study described, in addition to the isolation of anti-LNFPIII scFv genes, the purification of anti-LNFPIII scFv-Fc proteins from stably and transiently expressed cells and extracellular or intracellular localization of two anti-LNFPIII and three anti-Man3 scFv-Fc proteins. The results suggested that expression of anti-Man3 and other anti-carbohydrate antibodies in mammalian cells is disadvantageous for cell growth. In contrast to these anti-carbohydrate scFv-Fc proteins, the anti-insulin-like growth factor-I receptor $1 \mathrm{H} 7 \mathrm{scFv}-\mathrm{Fc}$ expressed in NS0 cells did not cause such problems [21]. In fact, over $400 \mathrm{mg}$ of the $1 \mathrm{H} 7 \mathrm{scFv}-\mathrm{Fc}$ proteins were continuously purified for use in in vivo studies [22,23]. Whether or not anti-carbohydrate antibodies in general are detrimental to mammalian cell survival needs to be further studied.

No.1 and 2 in Table 1 summarize the outcome of screening by the use of a new human scFvdisplaying phage library in combination with Man3- and LNFPIII-DPPE as carbohydrate probes. The results of mammalian cell expression of scFv-Fc antibodies published [16,20] are summarized in Table 2.

Table 1. Summary of the panning and screening of phages displaying human scFv proteins by various structurally-defined carbohydrate probes. The carbohydrate probes used are neoglycolipids (1-4), structures of which are illustrated in Figure 1a-c and Figure 2a, respectively, and Tn3-peptide (5), a peptide containing three consecutive Tn-antigens, as illustrated in Figure 2b.

\begin{tabular}{|c|c|c|c|c|c|}
\hline No. & $\begin{array}{l}\text { Carbohydrate } \\
\text { Probes Used }\end{array}$ & $\begin{array}{c}\text { Positive } \\
\text { Clones/Total } \\
\text { Clones Screened } \\
\text { (S/N Ratio) }\end{array}$ & $\begin{array}{c}\text { Phage Clones } \\
\text { with scFv } \\
\text { Gene }\end{array}$ & $\begin{array}{c}\text { Phage Clones } \\
\text { with scFv DNA } \\
\text { Sequence } \\
\text { Confirmed }\end{array}$ & $\begin{array}{l}\text { Phage Clones } \\
\text { Analyzed for } \\
\text { scFv Proteins }\end{array}$ \\
\hline 1 & $\begin{array}{l}\text { Mannotriose } \\
\text { (Man3)-DPPE }\end{array}$ & $\begin{array}{c}26 / 672 \\
(>2)\end{array}$ & 25 & 15 & $\begin{array}{l}5 \mathrm{~A} 3,1 \mathrm{~A} 4 \\
1 \mathrm{G} 4,5 \mathrm{C} 10\end{array}$ \\
\hline 2 & Le $^{\mathrm{x}}$ (LNFPIII)-DPPE & $\begin{array}{c}100 / 1,470 \\
(>4)\end{array}$ & 5 & 3 & $1 \mathrm{~F} 12,3 \mathrm{~F} 1$ \\
\hline 3 & T-antigen E6-BDB & $\begin{array}{c}25 / 96 \\
(>4)\end{array}$ & 22 & 11 & $\begin{array}{c}\text { 1E6, 1E8, } \\
1 \mathrm{E} 10,1 \mathrm{G} 11\end{array}$ \\
\hline 4 & Tn- antigen E6-BDB & $0 / 928$ & NA & NA & NA \\
\hline 5 & Tn3-peptide & $\begin{array}{l}8 / 96 \\
(>2) \\
\end{array}$ & 8 & 6 & $4 \mathrm{E} 10,4 \mathrm{G} 2$ \\
\hline
\end{tabular}


Table 2. Summary of the expression and purification of various scFv proteins in eukaryotic and prokaryotic cells.

\begin{tabular}{|c|c|c|c|c|}
\hline $\begin{array}{c}\text { Clone (Probe Used } \\
\text { for Screening) }\end{array}$ & $\begin{array}{c}\text { Antibody Constructs } \\
\text { Expressed } \\
\end{array}$ & $\begin{array}{c}\text { Cells Used } \\
\text { for Expression }\end{array}$ & Outcome & Reference \\
\hline 1A4, $1 \mathrm{G} 4$ (Man3-DPPE) & scFv-Fc/pEE12.4 & NS0 & No clone & [16] \\
\hline 1A4, 1G4 (Man3-DPPE) & scFv-Fc/pCI-neo & $\mathrm{CHO}$ & No clone & [16] \\
\hline 5A3 (Man3-DPPE) & scFv-Fc/pEE12.4 & NS0 & One clone & [16] \\
\hline 1F12 (LNFPIII-DPPE) & scFv-Fc/pEE12.4 & NS0 & One clone & [20] \\
\hline 3F1 (LNFPIII-DPPE) & scFv-Fc/pEE12.4 & NS0 & No clone & [20] \\
\hline 1G11 (T-antigen E6-BDB) & scFv/phagemid & $\begin{array}{c}\text { E. coli } \\
\text { TOP10F' }\end{array}$ & Soluble & [24] \\
\hline 4E10, 4G2 (Tn3-peptide) & $\mathrm{scFv} /$ phagemid & $\begin{array}{l}\text { E. coli } \\
\text { TOP10F' }\end{array}$ & Soluble & {$[25]$} \\
\hline $5 \mathrm{~A} 3,5 \mathrm{C} 10$ & GST-scFv/pGX-4T-1 & E. coli BL21 & Soluble & [16] \\
\hline 1A4, 1G4, 5A3 (Man3-DPPE) & scFv/pET22 & E. coli BL21 & $\begin{array}{c}\text { Inclusion } \\
\text { bodies }\end{array}$ & [26] \\
\hline $\begin{array}{c}\text { 1E6, 1E8 } \\
\text { (T-antigen E6-BDB) }\end{array}$ & scFv/pET22 & E. coli BL21 & $\begin{array}{c}\text { Inclusion } \\
\text { bodies }\end{array}$ & [27] \\
\hline $\begin{array}{c}\text { 1E8, 1E6 } \\
\text { (T-antigen E6-BDB) }\end{array}$ & $\begin{array}{c}\mathrm{scFv} / \mathrm{pMT} / \mathrm{Bip} / \mathrm{V5}- \\
\text { HIS }\end{array}$ & Drosophila $\mathrm{S} 2$ & Soluble & [28] \\
\hline
\end{tabular}

\section{Production and Characterization of Anti-T- and Tn-Antigen Antibodies}

Anti-T- and Tn-antigen scFvs were obtained using a strategy similar to the previously published method [15], except that differently designed neoglycolipids, as shown in Figure 1c and Figure 2a, respectively, were used for panning and screening. The $\mathrm{T}$ - and $\mathrm{Tn}$-antigen probes contained hexaethylene glycol (E6) as a spacer that was expected to reduce the non-specific binding of and to increase the accessibility to phage antibodies. Its lipid anchor, 3,5-bis-8-dodecyloxy benzamide (BDB), was also different from DPPE.

Of 96 phage clones screened from the phage library, 11 clones were shown to carry scFv sequences and had affinity for T-antigen E6-BDB (Figure 1c), a carbohydrate probe presenting T-antigen (No. 3 in Table 1). The DNA sequencing and ELISA of the 11 phage clones isolated revealed four groups of clones with T-antigen binding activity [24]. Of note is that a significantly high ratio of positive clones, $11.5 \%$ of the clones screened, was obtained. When anti-M3 scFvs were isolated using M3-DPPE as an antigen [15], only 15 out of 672 clones $(2.2 \%)$ with intact scFvs were obtained. In addition, unlike the isolation of M3 scFvs, in which 15 clones had all different sequences, three and two identical clones were obtained for Group 1 and 4 phages, respectively, when screened by Tantigen E6-BDB. Such a concentration of binding to an antigen during panning is in fact a good indication of possible positive clones being screened. The different outcomes from two studies may be due to the nature of their different carbohydrate moieties or the difference in the design of neoglycolipids used, namely the presence of E6 in the case of screening T-antigen scFvs. One scFv protein, derived from phage clone $1 \mathrm{G} 11$, was expressed in E. coli and purified to near homogeneity by two column chromatographies. ELISA and SPR analyses revealed that the purified $1 \mathrm{G} 11 \mathrm{scFv}$ protein bound to the T-antigen moiety of the neoglycolipid used [24]. 
In contrast, the panning and screening of phages with Tn-antigen E6-BDB (Figure 2a) did not yield any positive clones (No. 4 in Table 1). This result was not unexpected and clearly revealed that Tn-antigen, consisting of GalNAc, is too small to stably bind to the binding sites of antibodies. In fact, available anti-Tn antigen antibodies generally bind either two to three consecutive Tn-antigens, e.g., 83D4 or MLS128 [29-31], or Tn-antigen with a peptide backbone, e.g. 273mAb [32]. While unsuccessfully screening the phage display library with the Tn-antigen probe, we were extensively studying the MLS128 monoclonal antibody, which shows Tn3 and Tn2 specificity [33-36]. Based on those studies, Tn3-peptide, as shown in Figure 2b, was synthesized for the panning and screening of the phage library [25]. As summarized in Table 1 No. 5, eight positive phage clones out of 96 wells screened were identified, from which, two scFv proteins, $4 \mathrm{E} 10$ and $4 \mathrm{G} 2$, were purified and characterized [25].

Figure 2. Carbohydrate probes used for the panning and screening of phages displaying anti-Tn-antigen (a) Tn-antigen E6-BDB and (b) Tn3-peptide.

\section{a T n -antigen-E6-BDB}

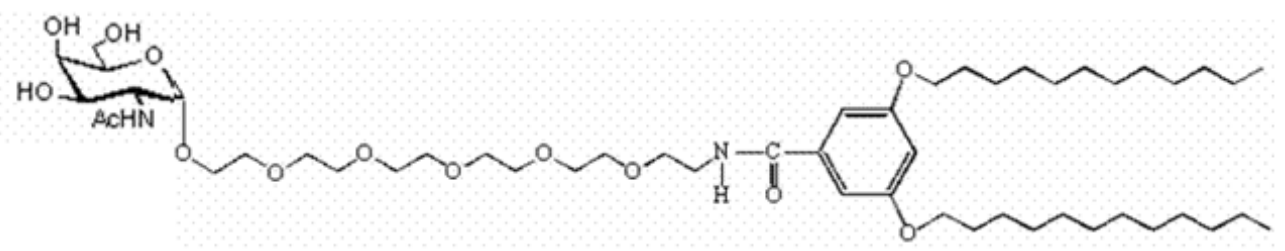

\section{b $\operatorname{Tn} 3$}

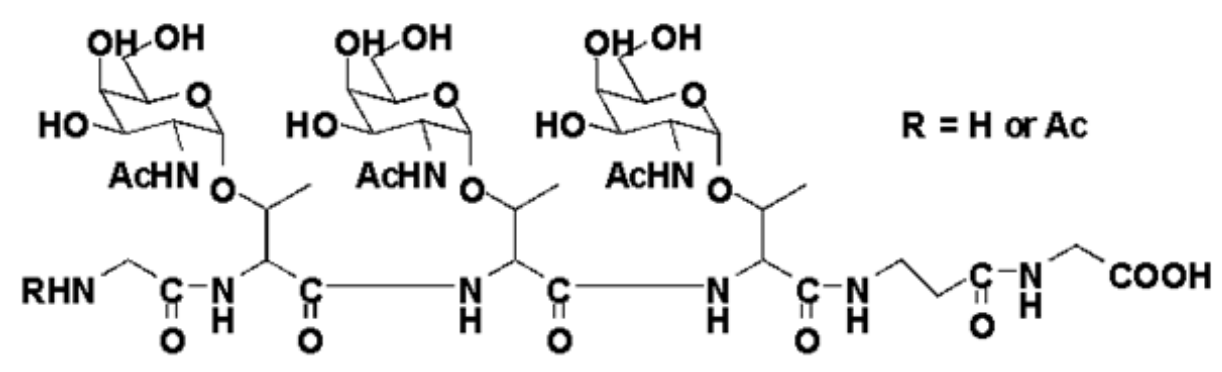

\section{Purification and Characterization of Anti-Carbohydrate Antibodies Expressed in E. coli Cells}

As mentioned in Section 2.1, the phage display strategy consists of two major components. The panning and screening of phage libraries (Component 1) can result in the isolation of genes coding recombinant antibodies. The design of phagemid should allow the expression of soluble antibody fragments from infected bacteria, so that crude $\mathrm{scFv}$ proteins can easily be prepared for analyses of their specificity. If lucky, purification and characterization of soluble scFv proteins can be completed in a short time. Unfortunately though, we found that the amounts of scFv proteins expressed and purified this way are usually not adequate for extensive analyses. In addition, it was inevitable to express the scFv proteins, not only for the detailed characterization of their specificity and affinity, but also for the future development of antibody therapeutics. Thus, isolated genes needed to be expressed in prokaryotic or eukaryotic cells to produce antibody proteins for further characterization of the respective genes obtained (Component 2). We found, however, that the expression of anti-Man3 and 
other anti-carbohydrate antibodies in mammalian cells, as described in Section 2.2, is disadvantageous for cell growth [20], and therefore, we needed to explore other non-mammalian expression systems. A summary of the expression and purification of various scFv proteins in eukaryotic and prokaryotic cells is tabulated (Table 2).

\subsection{Preparation of Soluble scFv Proteins from Phagemid-Infected E. coli Cells}

When initial analyses of anti-Man3 scFv proteins were carried out, the presence of scFv proteins was compared among supernatants, periplasmic fractions and whole cell extracts by sodium dodecyl sulphate polyacrylamide gel electrophoresis (SDS-PAGE) and immunoblotting, which revealed that the whole cell extract fractions contained the most scFv proteins expressed [15]. Thus, anti-T-antigen $1 \mathrm{G} 11 \mathrm{scFv}$ protein was purified from whole cell extracts of $1 \mathrm{G} 11$ phage-infected E. coli TOP 10F' cells that were induced by isopropyl $\beta$-D-thiogalactopyranoside (IPTG) to near homogeneity by two column chromatographies [24]. ELISA and SPR analyses confirmed the binding ability of purified $1 \mathrm{G} 11 \mathrm{scFv}$ protein to the T-antigen moiety of the neoglycolipid used [24]. Since the $1 \mathrm{G} 11$ protein was purified from total cell extracts, the purified protein must have included both peri-plasmic and cytosolic scFv proteins.

For purification of the anti-Tn3 scFv proteins, $4 \mathrm{E} 10$ and $4 \mathrm{G} 2$, peri-plasmic and cytosolic fractions were separately prepared from each phage-infected E. coli TOP $10 \mathrm{~F}^{\prime}$ cells after being induced by IPTG [25]. 4E10 and 4G2 proteins expressed in E. coli TOP10F' cells infected with 4E10 or 4G2 phages were purified by $\mathrm{Ni}^{2+}$-Sepharose from both periplasmic and cytosolic extracts. The amounts of the $\mathrm{scFv}$ proteins purified from periplasm and cytosolic extracts from a 100-mL culture were 50 and $275 \mu \mathrm{g}$, respectively, for 4E10, and 32.5 and $280 \mu \mathrm{g}$, respectively, for 4G2. Both 4E10 and 4G2 scFv proteins were purified from periplasmic extracts to near homogeneity by $\mathrm{Ni}^{2+}$-Sepharose chromatography. The purified periplasmic scFv proteins had Tn3-binding activity. In contrast, the scFv proteins purified from the cytosolic extracts were estimated to be $85 \%$ pure and did not have binding activity [25]. These results demonstrated that the $\mathrm{scFv}$ proteins synthesized were properly folded and translocated to periplasm, but that the production of soluble $\mathrm{scFv}$ proteins with binding activity suffered low yields.

\subsection{Purification and Characterization of scFv Proteins as Fusion Proteins}

The expression and purification of GST-scFv fusion protein were carried out using E. coli BL21 cells into which the recombinant expression plasmid, pGEX-4T-1-scFv (5A3 or 5C10), was introduced [16]. After the induction of soluble GST-5A3 or $-5 \mathrm{C} 10 \mathrm{scFv}$ fusion protein by IPTG, cells were disrupted with a sonicator. The supernatants containing fusion proteins were purified by Glutathione Sepharose 4B beads. As the control, the mock plasmid, pGEX-4T-1, which should express the GST protein alone at $29 \mathrm{kDa}$, was subjected to the same procedures of expression and purification as for the fusion protein. The GST-5A3 scFv fusion protein of $55 \mathrm{kDa}$ was expressed in a soluble form after induction by IPTG at concentrations of $0.01-0.2 \mathrm{mM}$ at $20^{\circ} \mathrm{C}$, since fusion proteins appeared to form inclusion bodies at 25,30 or $37{ }^{\circ} \mathrm{C}$. Although purified GST-5A3 scFv protein preparations contained some contaminants, they were pure enough for the following SPR analyses. Yields for the 
GST-5A3 and 5C10 scFv fusion proteins and GST protein alone were 1.2, 1.0 and $3.8 \mathrm{mg}$ from a $1,000 \mathrm{~mL}$ culture, respectively [16].

Although apart from phage display methods, we overproduced anti-Tn antibody MLS128 scFv protein as a fusion protein in E. coli cytoplasm using a novel pCold-protein disulfide isomerase (PDI) vector for the successful characterization of the purified scFv protein by NMR. This study showed that coupling with a PDI fusion tag enhances the soluble expression of disulfide-containing proteins, such as scFv proteins [35].

\subsection{Expression of scFv Proteins in E. coli by An Inducible T7 Expression System}

We previously reported the isolation and characterization of phages screened by a Man3-bearing lipid as an antigen from a phage library displaying human scFvs [15]. Four independent scFv genes, 1A4, 1G4, 5C10 and 5A3, were initially selected and characterized as phage antibodies [15]. Although the expression and purification of these $\mathrm{scFv}$ genes were not straightforward, $5 \mathrm{~A} 3$ and $5 \mathrm{C} 10 \mathrm{scFv}$ proteins were expressed and purified as a glutathione-S-transferase-scFv fusion protein in E. coli. The 5A3 gene was also successfully expressed and purified as an scFv-Fc form in NS0 cells, whereas NS0 or $\mathrm{CHO}$ stable clones expressing $1 \mathrm{~A} 4$ and $1 \mathrm{G} 4 \mathrm{scFv}-\mathrm{Fc}$ proteins had never been established [16]. In addition, a sharp decline in $5 \mathrm{~A} 3 \mathrm{scFv}-\mathrm{Fc}$ protein production was observed during the early passages of the stable NS0 cell culture [20]. Studies using COS-7 cells and a transient expression systems suggested that 1A4 and $1 \mathrm{G} 4 \mathrm{scFv}-\mathrm{Fc}$ proteins were synthesized, but retained in the ER, which may have impaired cell growth [20]. To avoid such severe problems associated with the mammalian expression systems, pET bacterial expression systems were used to produce and purify anti-Man3 1A4 and $1 \mathrm{G} 4 \mathrm{scFv}$ proteins, as well as $5 \mathrm{~A} 3 \mathrm{scFv}$ protein to compare their Man3-binding abilities [26].

$\mathrm{ScFv}$ genes of $1 \mathrm{~A} 4,1 \mathrm{G} 4$ and $5 \mathrm{~A} 3$ were subcloned into the pET-22b vector in order to express scFv proteins in E. coli. The pET expression system allows high level T7 RNA polymerase-based gene expression in E. coli BL21 (DE3) [26]. The constructs contained the pelB leader sequence at the amino-terminus and the His-tag sequence at the carboxyl-terminus, thus allowing the accumulation of expressed proteins in the periplasm and the detection or purification of the expressed protein, respectively. Conditions for the induction of $1 \mathrm{~A} 4$ and $1 \mathrm{G} 4 \mathrm{scFv}$ gene expression by IPTG were optimized to express scFv proteins in the periplasm. Periplasmic fractions were then prepared from IPTG-induced E. coli BL21 cells and subjected to $\mathrm{Ni}^{2+}$-Sepharose affinity chromatography to purify $1 \mathrm{~A} 4$ and $1 \mathrm{G} 4 \mathrm{scFv}$ proteins. The amounts of the scFv proteins purified from periplasm and cytosolic extracts from a $100-\mathrm{mL}$ culture were 120 and $420 \mu \mathrm{g}$, respectively, for $1 \mathrm{~A} 4$, and 76 and $576 \mu \mathrm{g}$, respectively, for $1 \mathrm{G} 4$. Analyses by SDS-PAGE and Western blotting indicated that $1 \mathrm{~A} 4$ and $1 \mathrm{G} 4 \mathrm{scFv}$ proteins were purified from periplasmic extracts to $\sim 80$ and $60 \%$ homogeneity, respectively. Although significant amounts of both $1 \mathrm{~A} 4$ and $1 \mathrm{G} 4 \mathrm{scFv}$ proteins were purified from cytosolic fractions, they did not exhibit significant binding activity. The binding activity of the periplasm-derived scFv proteins to Man3-DPPE examined by ELISA indicated that $1 \mathrm{~A} 4$ and $1 \mathrm{G} 4 \mathrm{scFv}$ proteins had binding affinity for Man3 [26].

Generally speaking, the purification of soluble forms of $\mathrm{scFv}$ proteins, which are usually folded correctly and, thus, expected to have binding activity, would be preferable. The results as described above, however, revealed that the yields of active scFv proteins purified from soluble fractions were 
too low to be practical. As the next step, abundant 1A4, 1G4 and 5A3 scFv proteins were recovered in inclusion bodies, which were then subjected to purification and refolding processes. Inclusion bodies were isolated from IPTG-induced E. coli BL21(DE3) cells transformed with pET22b/1A4, 1G4 or 5A3 expression vectors. Most of the insoluble proteins recovered as inclusion bodies were scFv proteins. Inclusion bodies were solubilized in $3.5 \mathrm{M}$ guanidine hydrochloride- $\mathrm{HCl}$, from which $\mathrm{scFv}$ proteins were purified by $\mathrm{Ni}^{2+}$-Sepharose chromatography in the presence of $3.5 \mathrm{M}$ guanidine hydrochloride- $\mathrm{HCl}$. The purified $\mathrm{scFv}$ proteins were refolded according to the stepwise dialysis method previously described [37], which resulted in 612,586 and $271 \mu \mathrm{g}$ of soluble $1 \mathrm{~A} 4,1 \mathrm{G} 4$ and $5 \mathrm{~A} 3 \mathrm{scFv}$ proteins, respectively, from $40 \mathrm{~mL}$ of culture. The resulting soluble scFv proteins were apparently homogenous, as judged by SDS-PAGE. The scFv proteins moved on the SDS-PAGE gel according to their theoretical molecular masses of $34.0,32.1$ and $33.7 \mathrm{kDa}$ for $1 \mathrm{~A} 4,1 \mathrm{G} 4$ and $5 \mathrm{~A} 3 \mathrm{scFv}$ proteins, respectively. ELISA and SPR analyses revealed that $1 \mathrm{G} 4 \mathrm{scFv}$ protein appears to have the highest binding activity, followed by $1 \mathrm{~A} 4 \mathrm{scFv}$ protein, and that the $5 \mathrm{~A} 3 \mathrm{scFv}$ protein has the lowest affinity for Man3 epitopes. These results are consistent with the working hypothesis that $1 \mathrm{~A} 4$ and $1 \mathrm{G} 4 \mathrm{scFv}-\mathrm{Fc}$ proteins having higher affinity for high mannose moieties are retained in ER, while 5A3 scFv-Fc protein avoids retention in the ER and is, therefore, secreted, when expressed in mammalian cells [20].

Four anti-T-antigen scFv genes belonging to Groups 1-4 were purified from inclusion bodies expressed in E coli cells, as described above. Two anti-T-antigen scFv proteins, 1E8 and 1E6, which belong to Groups 1 and 2, respectively, were produced in sufficient amounts, thus allowing further characterization of their binding activity with T-antigen. Specificity and affinity constants determined using ELISA and SPR, respectively, provided evidence that both 1E8 and 1E6 scFv proteins are $\mathrm{T}$-antigen specific and suggested that $1 \mathrm{E} 8 \mathrm{scFv}$ protein has a higher affinity for T-antigen than 1E6 scFv protein [27].

\section{Purification and Characterization of Anti-Carbohydrate Antibodies Expressed in Drosophila S2 Cells}

More recently, anti-T-antigen scFv genes belonging to Group 1-4 were expressed and produced in a Drosophila S2 cell expression system [28]. After S2 cells were co-transfected with each $\mathrm{pMT} / \mathrm{Bip} / \mathrm{scFv} / \mathrm{V} 5-H i s-\mathrm{B}$ vector and pCoHygro and cultured in selection medium for three weeks, the expression of scFv proteins was induced by $\mathrm{CuSO}_{4}$. S2 cells and cultured supernatants were harvested for the analysis of the expression and localization of scFv proteins in S2 cells using SDS-PAGE and Western blotting of cell homogenates and culture media. Coomassie Brilliant Blue (CBB)-stained SDS-PAGE gel clearly indicated that $1 \mathrm{E} 8 \mathrm{scFv}$ protein was expressed at a high level and secreted into the medium as expected. Although not visible in CBB-staining, the secretion of 1E6 and $1 \mathrm{E} 10 \mathrm{scFv}$ proteins was confirmed by Western blotting. In contrast, the expression of $1 \mathrm{G} 11 \mathrm{scFv}$ protein was only detected inside cells. Similarly, 1E6 and 1E10 scFv proteins were mostly recovered inside cells, which indicated the inhibition of $\mathrm{scFv}$ protein secretion. $\mathrm{ScFv}$ proteins were purified by $\mathrm{Ni}^{2+}$-Sepharose affinity chromatography from culture media. SDS-PAGE analysis revealed that $1 \mathrm{E} 8 \mathrm{scFv}$ protein was purified to near homogeneity, as observed in CBB staining. Although not detected in CBB-staining, Western blotting confirmed that $1 \mathrm{E} 6$ and $1 \mathrm{E} 10 \mathrm{scFv}$ proteins, $8 \mathrm{mg}$ and $0.67 \mathrm{mg}$, respectively, were purified to near homogeneity from $1,000 \mathrm{~mL}$ of $\mathrm{S} 2$ cell culture. $1 \mathrm{E} 8 \mathrm{scFv}$ protein was expressed at 
comparable levels as previously mentioned [38]. ELISA and SPR analyses confirmed the binding activity of $1 \mathrm{E} 8 \mathrm{scFv}$ protein to various $\mathrm{T}$-antigen presenting conjugates. NMR experiments provided evidence of the folded nature of the $1 \mathrm{E} 8 \mathrm{scFv}$ protein. ScFv-ligand contact was identified by saturation transfer difference (STD) NMR, indicating that the galactose unit of T-antigen at the non-reducing end was primarily recognized by $1 \mathrm{E} 8 \mathrm{scFv}$. This thus provided direct evidence of T-antigen specificity [28].

\section{Conclusion}

After carrying out a decade of laborious and continuous hard work, I must admit that our original idea of producing a variety of carbohydrate epitope-specific antibodies by phage display technology was rather naive. Tables 1 and 2 summarize the results of successful experiments, as well as unsuccessful ones. We have succeeded in obtaining several genes for human anti-carbohydrate scFv proteins that may contribute to future developments in basic and clinical research. The most advanced data have been obtained for the detailed binding of T-antigen disaccharide to $1 \mathrm{E} 8 \mathrm{scFv}$ protein by STD NMR [28]. In conclusion, each scFv protein was unique, so that its production needed to be optimized, that is to say, active soluble $\mathrm{scFv}$ proteins were purified from periplasmic fractions of phagemid-infected $E$. coli cells at $\sim 0.5 \mathrm{mg} / 1,000 \mathrm{~mL}$ or from IPTG-induced $E$. coli cells transformed with $\mathrm{pET} 22 \mathrm{~b} / \mathrm{scFv}$ vectors at the $\sim 1 \mathrm{mg} / 1,000 \mathrm{~mL}$ level, while better yields at the $\sim 10 \mathrm{mg} / 1,000 \mathrm{~mL}$ level were achieved from the purification and refolding of $\mathrm{scFv}$ proteins from inclusion bodies. The expression and purification of $\mathrm{scFv}$ proteins as fusion proteins in E. coli and the purification of $\mathrm{scFv}$ proteins expressed in Drosophila S2 cells apparently seem to be good strategies for anti-carbohydrate antibodies.

\section{Acknowledgments}

This work was supported in part by a grant from the Core Research Evolutional Science and Technology (CREST) Project, the Japan Science and Technology Agency (JST), and grants 17570120 and 22570125 from the Japan Society for the Promotion of Science.

\section{Conflicts of Interest}

The authors declare no conflict of interest.

\section{References}

1. Vos, Q.; Lees, A.; Wu, Z.Q.; Snapper, C.M.; Mond, J.J. B-cell activation by T-cell-independent type 2 antigens as an integral part of the humoral immune response to pathogenic microorganisms. Immunol. Rev. 2000, 176,154-570.

2. Heimburg-Molinaro, J.; Lum, M.; Vijay, G.; Jain, M.; Almogren, A.; Rittenhouse-Olson, K. Cancer vaccines and carbohydrate epitopes. Vaccine 2011, 29, 8802-8826.

3. Cunto-Amesty, G.; Dam, T.K.; Luo, P.; Monzavi-Karbassi, B.; Brewer, C.F.; Van Cott, T.C.; Kieber-Emmons, T. Directing the immune response to carbohydrate antigens. J. Biol. Chem. 2001, 276, 30490-30498. 
4. Hakomori, S. Tumor-associated carbohydrate antigens defining tumor malignancy: Basis for development of anti-cancer vaccines. Adv. Exp. Med. Biol. 2001, 491, 369-402.

5. Marks, J.D.; Hoogenboom, H.R.; Bonnet, T.P.; McCafferty, J.; Griffiths, A.D.; Winter, G. By-passing immunization. Human antibodies from V-gene libraries displayed on phage. J. Mol. Biol. 1991, 222, 581-597.

6. $\quad$ Deng, S.; MacKenzie, C.R.; Sadowaka, J.; Michniewicz, J.; Young, N.M.; Bundle, D.R.; Narang, S.A. Selection of antibody single-chain variable fragments with improved carbohydrate binding by phage display. J. Biol. Chem. 1994, 269, 9533-9538.

7. MacKenzie, C.R.; Hirama, T.; Deng, S.; Bundle, D.R.; Narang, S.A.; Young, N.M. Analysis by surface plasmon resonance of the influence of valence on the ligand binding affinity and kinetics of an anti-carbohydrate antibody. J. Biol. Chem. 1996, 271, 1527-1533.

8. Springer, G.F. Immunoreactive $\mathrm{T}$ and $\mathrm{Tn}$ epitopes in cancer diagnosis, prognosis, and immunotherapy. J. Mol. Med. 1997, 75, 594-602.

9. Van Kuppevelt, T.H.; Dennissen, M.A.B.A.; van Venrooij, W.J.; Hoet, R.M.A.; Veerkamp, J.H. Generation and application of type-specific anti-heparan sulfate antibodies using phage display technology. Further evidence for heparan sulfate heterogeneity in the kidney. J. Biol. Chem. 1998, 273, 12960-12966.

10. Mao, S.; Gao, C.; Lo, C.-H.L.; Wirsching, P.; Wong, C.-H.; Janda, K.D. Phage-display library selection of high-affinity human single-chain antibodies to tumor-associated carbohydrate antigens sialyl Lewisx and Lewisx, Proc. Natl. Acad. Sci. USA 1999, 96, 6953-6958.

11. Lee, K.J.; Mao. S.; Sun, C.; Gao, C.; Blixt, O.; Arrues, S.; Hom, L.G.; Kaufmann, G.F.; Hoffman, T.Z.; Coyle, A.R.; et al. Phage-display selection of a human single-chain fv antibody highly specific for melanoma and breast cancer cells using a chemoenzymatically synthesized G(M3)-carbohydrate antigen. J. Am. Chem. Soc. 2002, 124, 12439-12446.

12. Ravn, P.; Danielczyk, A.; Jensen, K.B.; Kristensen, P.; Christensen, P.A.; Larsen, M.; Karsten, U.; Goletz, S. Multivalent scFv display of phagemid repertoires for the selection of carbohydratespecific antibodies and its application to the Thomsen-Friedenreich antigen. J. Mol. Biol. 2004, 343, 985-996.

13. Stoll, M.S.; Mizuochi, T.; Childs, R.A.; Feizi, T. Improved procedure for the construction of neoglycolipids having antigenic and lectin-binding activities, from reducing oligosaccharides. J. Biochem. 1988, 256, 661-665.

14. Shimizu, Y.; Nakata, M.; Matsunuma, J.; Mizuochi, T. Simultaneous quantification of components of neoglycolipid-coated liposomes using high-performance liquid chromatography with evaporative light scattering detection. J. Chromatogr. B. Biomed. Sci. Appl. 2001, 754, 127-133.

15. Sakai, K.; Shimizu, Y.; Chiba, T.; Matsumoto-Takasaki, A.; Kusada, Y.; Zhang, W.; Nakata, M.; Kojima, N.; Toma, K.; Takayanagi, A.; et al. Isolation and characterization of phage-displayed single chain antibodies recognizing non-reducing terminal mannose residues. 1. A new strategy for generation of anti-carbohydrate antibodies. Biochemistry 2007, 46, 253-262.

16. Zhang, W.; Matsumoto-Takasaki, A.; Kusada, Y.; Sakaue, H.; Sakai, K.; Nakata, M.; FujitaYamaguchi, Y. Isolation and characterization of phage-displayed single chain antibodies recognizing non-reducing terminal mannose residues. 2. Expression, purification, and characterization of recombinant single chain antibodies. Biochemistry 2007, 46, 263-270. 
17. Vaughan, T.J.; Williams, A.J.; Pritchard, K.; Osbourn, J.K.; Pope, A.R.; Earnshaw, J.C.; McCafferty, J.; Hodits, R.A.; Wilton, J.; Johnson, K.S. Human antibodies with subnanomolar affinities isolated from a large non-immunized phage display library. Nat. Biotechnol. 1996, 14, 309-314.

18. Sblattero, D.; Bradbury, A. A definitive set of oligonucleotide primers for amplifying human V regions. Immunotechnology 1998, 3, 271-278.

19. Sheets, M.D.; Amersdorfer, P.; Finnern, R.; Sargent, P.; Lindovist, E.; Schier, R.; Hemingsen, G.; Wong, C.; Gerhart, J.C.; Marks, J.D. Efficient construction of a large nonimmune phage antibody library: The production of high-affinity human single-chain antibodies to protein antigens. Proc. Natl. Acad. Sci. USA 1998, 95, 6157-6162.

20. Yuasa, N.; Zhang, W.; Goto, T.; Sakaue, H.; Matsumoto-Takasaki, A.; Kimura, M.; Ohshima, H.; Tsuchida, Y.; Koizumi, T.; Sakai, K.; et al. Production of anti-carbohydrate antibodies by phagedisplay technologies: Potential impairment of cell growth as a result of endogenous expression. J. Biol. Chem. 2010, 285, 30587-30597.

21. Li, S.-L.; Liang, S.-J.; Guo, N.; Wu, A.M.; Fujita-Yamaguchi, Y. Single chain antibodies against human insulin-like growth factor-I receptor: Expression, purification, and effect on tumor growth. Cancer Immunol. Immunother. 2000, 49, 243-252.

22. Guo, N.; Ye, J.-J.; Liang, S.-J.; Mineo, M.; Li, S.L.; Giannini, S.; Plymate, S.R.; Sike, R.A.; Fujita-Yamaguchi, Y. The role of insulin-like growth factor-II in cancer growth and progression evidenced by the use of ribozymes and prostate cancer progression models. Growth Horm. IGF Res. 2003, 13, 44-53.

23. Sachdev, D.; Li, S.-L; Hartell, J.S.; Fujita-Yamaguchi, Y.; Miller , J.S.; Yee, D. A chimeric humanized single chain antibody against the type I insulin-like growth factor receptor renders breast cancer cells refractory to the mitogenic effects of insulin-like growth factor-I. Cancer Res. 2003, 63, 627-635.

24. Matsumoto-Takasaki, A.; Horie, J.; Sakai, K.; Furui, Y.; Sato, R.; Kawakami, H.; Toma, K.; Takayanagi, A.; Shimizu, N.; Fujita-Yamaguchi, Y. Isolation and characterization of anti-Tantigen single chain antibodies from a phage library. Biosci. Trends. 2007, 3, 87-95.

25. Sakai, K.; Yuasa, N.; Tsukamoto, K.; Takasaki-Matsumoto, A.; Yajima, Y.; Sato, R.; Kawakami, H.; Mizuno, M.; Takayanagi, A.; Shimizu, N.; et al. Isolation and characterization of antibodies against three consecutive Tn-antigen clusters from a phage library displaying human single-chain variable fragments. J. Biochem. 2010, 147, 809-817.

26. Matsumoto-Takasaki, A.; Yuasa, N.; Katagiri, D.; Koyama, T.; Sakai, K.; Zamri, N.; Phung, S.; Chen, S.; Nakada, H.; Nakata, M.; et al. Characterization of three different single chain antibodies recognizing nonreducing terminal mannose residues expressed in Escherichia coli by an inducible T7 expression system. J. Biochem. 2011, 150, 439-450.

27. Yuasa, N.; Koyama, T.; Fujita-Yamaguchi, Y. Purification and refolding of anti-T-antigen single chain antibodies (scFvs) expressed in E. coli as inclusion bodies. Biosci. Trends, 2014, 8, 24-31.

28. Yuasa, N.; Koyama, T.; Subedi, G.P.; Yamaguchi, Y.; Matsushita, M.; and Fujita-Yamaguchi, Y. Expression and structural characterization of anti-T-antigen single chain antibodies (scFvs) and analysis of their binding to T-antigen by surface plasmon resonance and NMR spectroscopy. J. Biochem. 2013, 154, 521-529. 
29. Numata, Y.Y.; Nakada, H.; Fukui, S.; Kitagawa, H.; Ozaki, H.; Inoue, K.; Kawasaki, M.; Funakoshi, T.; Yamashina, I. A monoclonal antibody directed to Tn antigen. Biochem. Biophys. Res. Commun. 1990, 170, 981-985.

30. Pancino, G.F.; Osinaga, E.; Vorauher, W.; Kakouche, A.; Mistro, D.; Charpin, C.; Roseto, A. Production of a monoclonal antibody as immunohistochemical marker on paraffin embedded tissues using a new immunization method. Hybridoma 1990, 9, 389-395.

31. Osinaga, E.; Bay, S.; Tello, D.; Babino, A.; Pritsch, O.; Assemat, K.; Cantacuzene, D.; Nakada, H.; Alzari, P. Analysis of the fine specificity of Tn-binding proteins using synthetic glycopeptide epitopes and a biosensor based on surface plasmon resonance spectroscopy. FEBS Lett. 2000, 469, 24-28.

32. Schietinger, A.; Philip, M.; Yoshida, B.A.; Azadi, P.; Liu, H.; Meredith, S.C.; Schreiber, H. A mutant chaperone converts a wild-type protein into a tumor-specific antigen. Science 2006, 314, 304-308.

33. Matsumoto-Takasaki, A.; Hanashima, S.; Aoki, A.; Yuasa, N.; Ogawa, H.; Sato, R.; Kawakami, H.; Mizuno, M.; Nakada, H.; Yamaguchi, Y.; et al. Surface plasmon resonance and NMR analyses of anti Tn-antigen MLS128 monoclonal antibody binding to two or three consecutive Tn-antigen cluster. J. Biochem. 2012, 151, 273-282.

34. Yuasa, N.; Ogawa, H.; Koizumi, T.; Tsukamoto, K.; Matsumoto-Takasaki, A.; Asanuma, H.; Nakada, H.; Fujita-Yamaguchi, Y. Construction and expression of anti-Tn-antigen-specific single chain antibody genes from hybridoma producing MLS128 monoclonal antibody. J. Biochem. 2012, 151, 371-381.

35. Subedi, G.P.; Satoh, T.; Hanashima, S.; Ikeda, A.; Nakada, H.; Sato, R.; Mizuno M.; Yuasa, N.; Fujita-Yamaguchi, Y.; Yamaguchi, Y. Overproduction of anti-Tn antibody MLS128 single-chain Fv fragment in Escherichia coli cytoplasm using a novel pCold-PDI vector. Protein Expr. Puri. 2012, 82, 197-204.

36. Fujita-Yamaguchi, Y. Renewed interest in basic and applied research involving monoclonal antibodies against an oncofetal Tn-antigen. J. Biochem. 2013, 152, 103-105.

37. Umetsu, M.; Tsumoto, K.; Hara, M.; Ashish, K.; Goda, S.; Adschiri, T.; Kumagai, I. How additives influence the refolding of immunoglobulin-folded proteins in a stepwise dialysis system. Spectroscopic evidence for highly efficient refolding of a single-chain Flv fragment. J. Biol. Chem. 2003, 278, 8979-8987.

38. Gilmartin, A.A.; Lamp, B.; Rümenapf, T.; Persson, M.A.; Rey, F.A.; Krey, T. High-level secretion of recombinant monomeric murine and human single-chain $\mathrm{Fv}$ antibodies from Drosophila S2 cells. Protein Eng. Des. Sel. 2012, 25, 59-66.

(C) 2014 by the authors; licensee MDPI, Basel, Switzerland. This article is an open access article distributed under the terms and conditions of the Creative Commons Attribution license (http://creativecommons.org/licenses/by/3.0/). 